\title{
ПСИХОЛОГИЧЕСКИЕ ПРИНЦИПЫ ПРОЕКТИРОВАНИЯ СИСТЕМЫ ПРОФЕССИОНАЛЬНОГО ОБУЧЕНИЯ
}

\author{
Агузумцян P.B. \\ Национальное бюро экспертиз, \\ Ереван, Армения
}

Статья посвящена психологическим принципам проектирования системы профессионального обучения. Предложены четыре уровня анализа профессиональной деятельности, и изложены взгляды на проблемы структуры деятельности, функции специалиста и его психических реакций. Особое внимание уделено проведенному психологическому анализу деятельности, который позволил создать «психологический паспорт» конкретной психологической деятельности. Обосновывается идея о том, что, на основе психологического паспорта возможно организовать процессы профессионального психологического отбора, обучения, подготовки и переподготовки специалиста. Представлены классификации методов обучения, прочесса фрормирования навыка и классификации умений. В заключении приведена постадийность организации системы фрормирования профессиональной деятельности.

Ключевые слова: обучение, профессиональная подготовка, эффрективность подготовки, средства обучения, психологический тренажер

Современное состояние, тенденции и динамика развития сложных систем уравнения предъявляют особые требования к эфффективности деятельности специалиста. По данным различных исследователей количество ошибок при принятии и использовании решений человеком составляет от $20 \%$ до $80 \%$. При этом, в основе вина не самого специалиста, а причины, которые обусловлены системами психологического отбора, обучения, подготовки, переподготовки и организации его деятельности, а также несоответствие техники психофизиологическим характеристикам человека.

Проектирование деятельности специалиста представляет собой не только составление алгоритмов деятельности (действий или операций и логических условий их выполнения), но и анализ и проектирование психологических механизмов управляющих этой деятельностью.

Анализ профрессиональной деятельности может быть проведен на четырех уровнях:

- анализ на уровне формирования мотива - цели деятельности;

- психологический анализ деятельности в процессе его выполнения;

- анализ орудия труда как средства достижения цели;

- анализ формирования субъекта профессиональной деятельности.

Проектирование профессиональной деятельности включает в себя разработку структуры деятельности, функций специалиста и его психических реакций, а реализация проекта деятельности обеспечивается профессиональной ориентацей, профрессиональным отбором и обучением. В процессе профессиональной подготовки специалистов необходимо решать следующее задачи:

\footnotetext{
Адрес для корреспонденции: Агузумцян Рубен Вазгенович, начальник отдела психологических экспертиз Националного бюро экспертиз Республики Армения, 0004, РА, г.Ереван, пр. Адмирала Исакова, 24, rvaghuzumtsyan@list.ru
} 
- формирование и развитие профрессионально важных качеств;

- построение широкого спектра средств для диагностики, формирование и закрепление профессионально важных психических функций (памяти, внимания, мышления, скорости реакций и т.п.), отдельных специализированных компонентов деятельности, средств для отработки последовательности заданий (включая задачи с экстремальными условиями выполнения) и комплексных средств, способных имитировать условия деятельности специалистов, максимально приближенные к их работе в реальных условиях.

Психологический анализ деятельности позволяет создать “психологический паспорт” конкретной профессиональной деятельности, который состоит, как из общих психологических качеств, так и отдельных (специальных) профессионально важных психологических качеств (ПВПК). На основе психологического паспорта организуются процессы профессионального психологического отбора, обучения, подготовки и переподготовки. В результате профессионального отбора составляется психологический портрет конкретного специалиста, который в процессе подготовки должен максимально быть приближен по своим характеристикам к психологическому портрету профессиональной деятельности. Одним из путей решения данной проблемы является создание и применение психологических тренажёров. Другим направлением является разработка автоматизированных систем обучения (АСО) с использованием современных средств вычислительной техники, с помощью которых будут формироваться знания и ПВПК.

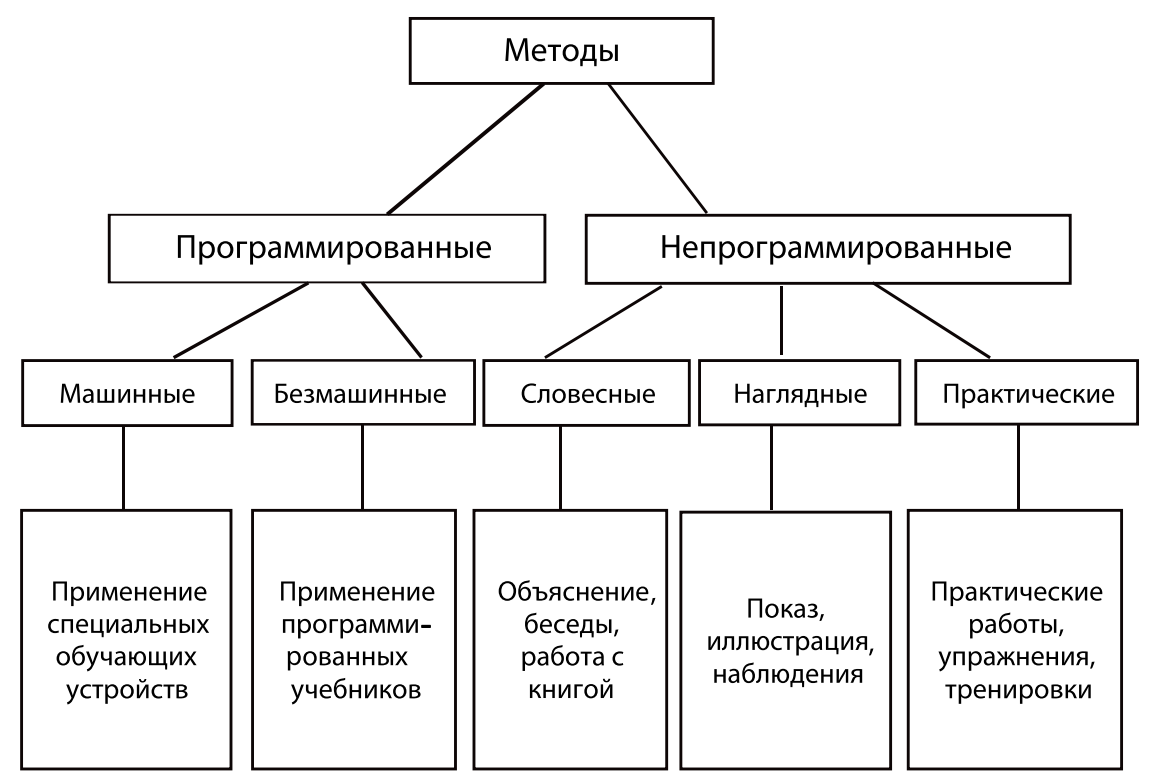

Рис. 1. Классификация методов обучения

Все этапы деятельности обеспечивают эффрективность действий специалиста, но особое внимание в большой степени, необходимо уделять процессам обучения и подготовки.

С психологической точки зрения знания могут выступать в фрорме наглядных представлений (образов) и понятий являющихся абстрактным и обобщенным отражением действительности. Одним из существенных свойств системы знаний специалиста является упорядоченность, когда наглядные представления переводятся в понятия и наоборот. 
В процессе обучения, жизни и деятельности каждый человек, как известно, естественно, накапливает знания, относящиеся к различным областям. При этом одни усвоенные знания могут служить основой и содействовать овладению новыми знаниями, а другие возможно возникновению взаимной интерференции знаний. Эти моменты важно учитывать в организации обучения, определения последовательности тем, дозировки материала, передаваемого обучающему лицу.

Эфффективность и наглядность действий специалиста определяется не только имеющимися знаниями, но и гибкостью и своевременностью выполняемых им действий.

Навык - это способность в процессе целенаправленной деятельности выполнять отдельные действия автоматизировано, без специально направленного внимания, но под контролем. Основным средством формирования навыка является упражнение.

Как правило, “автоматизировать” следует лишь те действия, которые характеризуются известным однообразием и выполняются по некоторым шаблонам.

При обучении той или иной деятельности необходимо установить , какие именно действия целесообразно довести до “автоматизма”. В психологии различают три основных вида навыков: сенсорно-перцептивные (навыки восприятия), моторные (двигательные навыки) и умственные.

Формирование любого навыка, как правило, должно иметь определенные черты:

- целостность элементов действия, например умственных актов;

- устранение ненужных действий и снижение психофизиологического напряжения;

- направление внимания с исполнения действий на результат;

- соблюдение ритма выполняемых движений, что является важным для обеспечения долгосрочной работы без усталости;

- возможность произвольного изменения темпа деятельности.

В процессе фрормирования навыка последний разграничивают на определенные этапы.

Первый этап - предварительный. На этом этапе происходит формирование программы навыка, расчленение отдельных движений на компоненты, производятся пробные, ориентировочные движения.

Второй - аналитический. Движения на этом этапе выполняются раздельно, происходит чувственный анализ силы, величины, длительности каждого движения.

Третий - синтетический. Отдельные элементы объединяются в одно целое.

Четвертый - этап автоматизации. На этом этапе происходит устранение излишних движений и излишней напряженности. Создаются условия по переносу внимания с исполнения действий на конечную цель, а также по управлению темпа работ.

Дальнейшее повышение обобщенности усвояемых действий достигается повторением разнородности действий. Таким образом, вариативность условий обучения является необходимым фактором формирования гибких, легко переносимых в новые условия навыков.

При сложностях приобретения навыков используются определенные приемы:

а) тренировки, применяющиеся в случаях невыполнения соответствующего ритма работы обучаемого из-за ошибок внимания;

б) методические рекомендации при появлении неожиданной информации, когда обучаемый ошибочно анализирует ее, при этом сигнал обратной связи не функционирует;

в) инструкции, заключающиеся в том, что обучаемый, получивший и усвоивший их, активно воспроизводит словесное содержание и одновременно выполняет заданные действия, при этом 
инструктаж выполняется в том случае, когда обучаемый затрудняется объединить в единый образ усвоенные представления и непосредственные ощущения возникающие в ходе работы;

г) технологические решения по разрешению затруднений планирования последовательности рабочих действий при одновременном поступлении письменных указаний.

Как и усваиваемые знания, формируемые навыки, способны интерферироваться с ранее образованными, что также надо учитывать при обучении специалистов.

Наиболее полно в психологии изучены моторные навыки, их характеристики и закономерности формирования. Они могут быть с определенными поправками отнесены к сенсорно-перцептивным и умственным навыкам.

Формирование двигательных навыков разделяют на три этапа.

Первый этап - изучение отдельных элементов движения с объединением их в одно целостное действие (этот этап характеризуется наличием лишних, нецелесообразных движений).

Второй этап - нецелесообразные движения исчезают, движения более точны, ослабевает длительный контроль, увеличивается роль двигательного контроля.

Третий этап - динамический стереотип большинства действий выполняется автоматически, сознание только контролирует действия.

При формировании сложного моторного навыка частичные навыки, входящие в него, не только суммируются, но и выполняются в несколько приемов, одновременно требующих иногда перестройки каждого из частичных навыков. При фрормировании сложных навыков возможна временная задержка или наличие так называемого плато на кривой упражнения (рис.2).

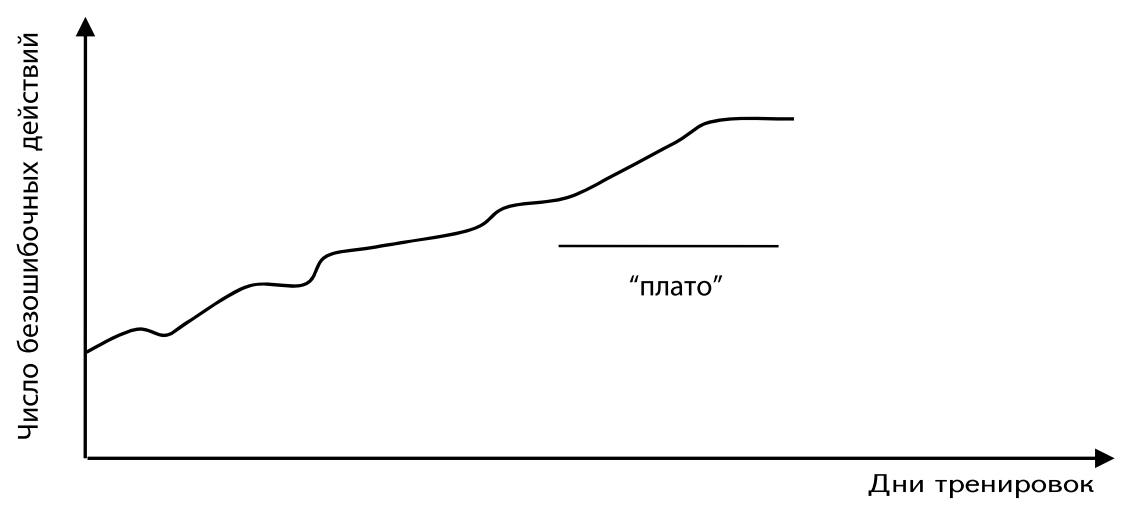

Рис. 2 Кривая продуктивности моторного навыка

Причинами возникновения такой задержки могут быть утомление, понижение интереса к упражнению, ослабление внимания или торможение хода развития навыка вследствие необходимости изучения новых приемов его выполнения.

Следует учесть, что ранее усвоенные приемы могут даже тормозить образование и закрепление новых навыков. Таким образом, задержка развития навыков означает, что старые методы и приемы выполнения действий становятся неэффективными и обучаемый должен перейти на новые.

Навыки, как уже было отмечено выше, фрормируются в процессе упражнения (тренировки). Для того, чтобы упражнение при фрормировании навыка было эффективным, оно должно удовлетворять следующим требованиям. Необходимо, чтобы обучаемый:

- понимал цель и значения обучаемого навыка и стремился овладеть им; 
- знал о достигнутых им результатах, понимать причины допущенных ошибок и пути их преодоления.

- понимал, какие действия и упражнения являются наиболее существенными, главными и какие второстепенными.

Нецелесообразно предъявлять обучаемому сразу много требований. Чтобы у обучаемого не выработался бы неправильный навык, необходимо следить за правильным выполнением основных немногочисленных требований, которые обязательны для формирования правильного навыка. На начальной стадии фрормирования навыка лучше ориентироваться на точность и последовательность выполнения приемов, чем на скорость, так как поспешность может привести к закреплению ошибок. Целостные действия, по возможности, необходимо расчленять на частные, которые легче усваивать по отдельности.

Эфрфективность формирования навыка зависит от правильного распределения упражнений по времени. Они не должны быть чрезмерно частыми, но и не быть редкими, чтобы не разрушались уже сорормированные и формирующиеся навыки.

Продуктивность навыка зависит от методики обучения, способностей обучаемых и их эмоциональных состояний. Поэтому в процессе обучения необходимо мобилизовать психику обучаемых, возбуждая в них интерес к выполняемым упражнениям.

Большое значение имеют полнота и определенность инструкции, которая должна содержать все необходимые сведения и не допускать различного ее понимания.

Очень важно, чтобы инструкция была своевременной.

На базе знаний навыков фрормируется умение - способности человека самостоятельно выполнять определенную работу. Оно проявляется при решении нестандартных задач, предполагает хорошую ориентировку работника в новых условиях и выступает не как простое повторение прошлого опыта, требуя творческого подхода.

Важнейшим для любого вида деятельности является умение работника самостоятельно ее планировать. В процессе планирования специалист оценивает не только условия своего труда и определенные требования к его результату, но и свои собственные силы (особенно динамику работоспособности). Планирование своей деятельности должно включать прогнозирование хода управляемого процесса и оценку вероятности возникновения тех или иных событий (например, аварий). Классификация умений схематически показана на рис. 3.

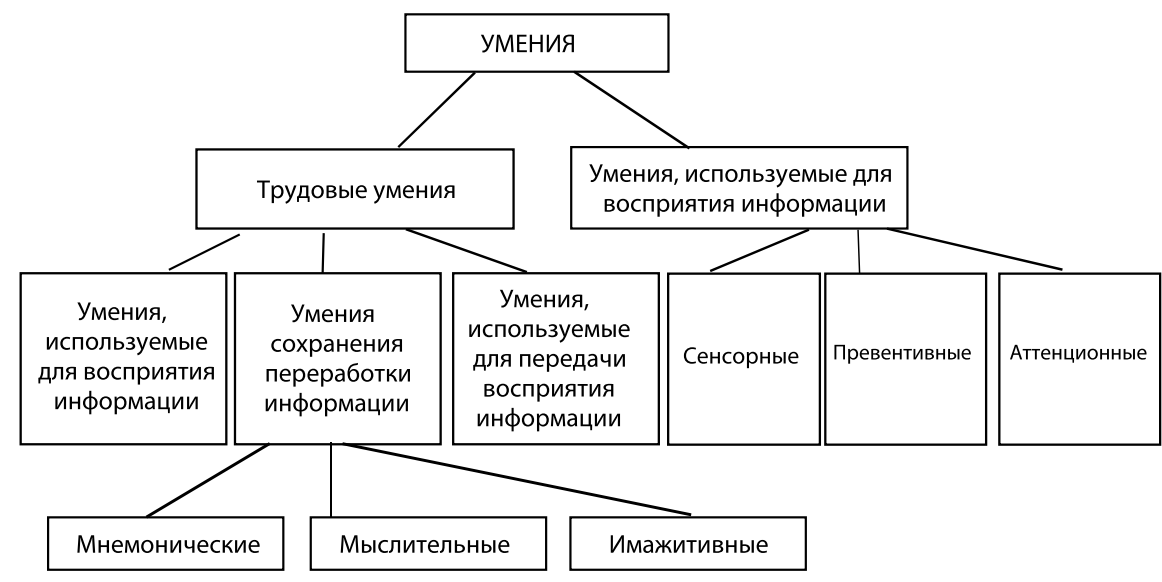

Puc. 3. Классификация умений

Умения, при обработке специалистами поступающей информации, подразделяются на три вида: 
- применяемые для обработки поступающей информации,

- применяемые для активации памяти,

- применяемые для передачи обработанной информации.

Эффрективность и надежность профессиональной деятельности определяется системным характером методологии в вопросе учета всех вышерассмотренных параметров, определяющих профессионального специалиста. Поэтапность решения данной проблемы определяется следующими фрактами:

- описанием психологической сути профессии /профессиограмма/;

- выявляемыми психическими качествами (психограмма);

- разработкой и определением методов оценки психических качеств;

- организацией профессионального психологического отбора;

- организацией профессионального обучения и подготовки кадров;

- организацией процесса переподготовки кадров.

Надежность деятельности специалиста определяется строгим соблюдением перечисленных этапов и соответствующих процедур.

В заключение необходимо подчеркнуть основное правило определяющее благосостояние общества, государства, организаций и отдельного гражданина/специалиста - кадры определяют это благосостояние, а бережная, научно обоснованная организация деятельности человека является гарантом благополучия.

\section{Список литературы}

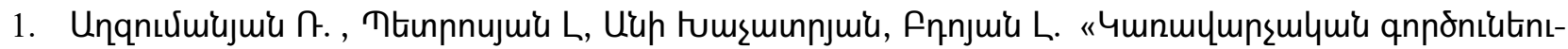

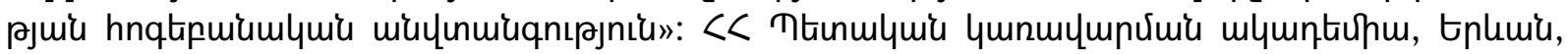
2017p. :

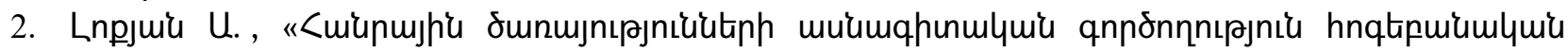

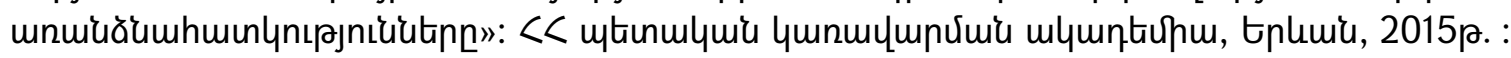

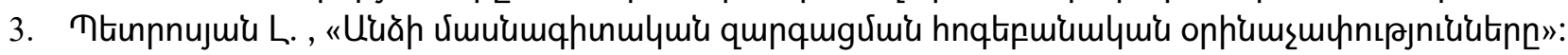

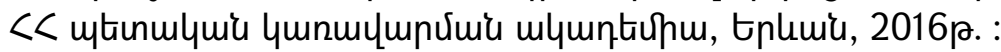

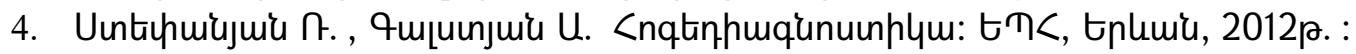

5. Журовлев А.Л., Нестик Т.А., “Психология управления совместной деятельностью», Институт психологии РАН, Москва, 2010г.

6. “Личность профессионала в современном мире”. Отв. редакторы: Дикая Л. Г., Журавлев А. Х., Институт психологии РАН, Москва, 2013г.

7. Проблемы психологической безопасности личности: Теоретические и экспериментальные исследования. Коллективная монография. Агузумцян Р.В., Амирян С. С., Папоян Р.Р., Мурадян Е.Б., Галстян А.С., Саргсян Д. Ю.. ЕГУ, Ереван, 2013г.

8. “Психология и педагогика высшей школы”, Учебник. Авторский коллектив: Столяренко Л. Д. и др., Изд. “Феникс", Ростов-на Дону, 2014г.

9. Форель К., “Психологические принципы обучения взрослых”, Изд. “Генезис”, Москва, 2010г. 


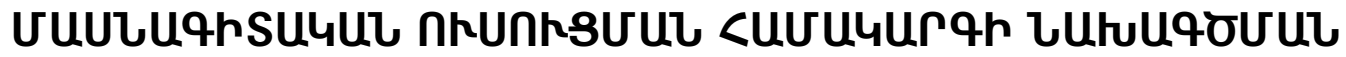

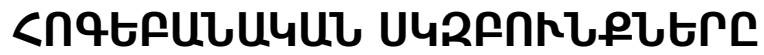

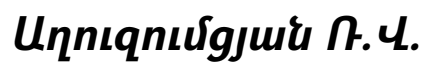

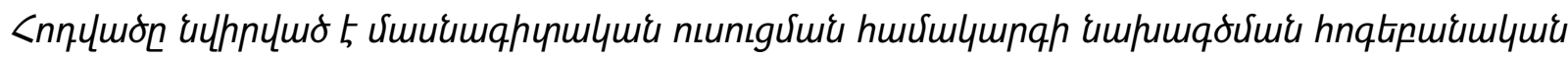

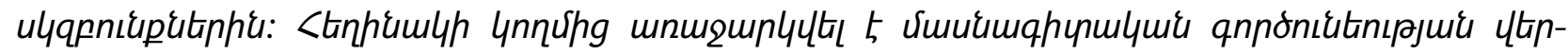

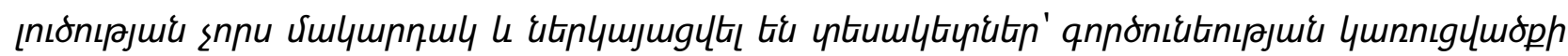

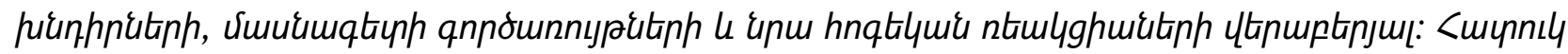

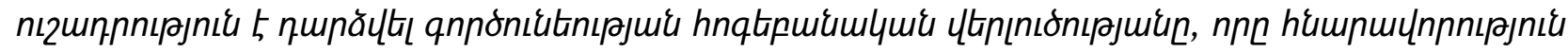

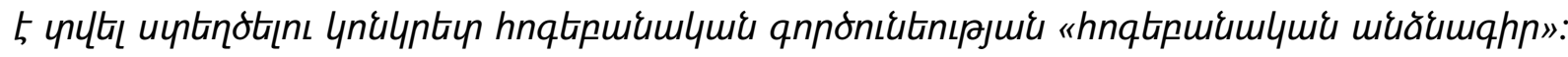

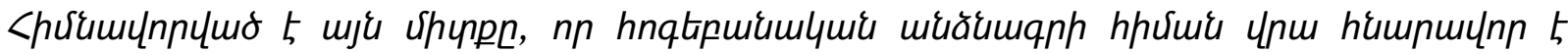

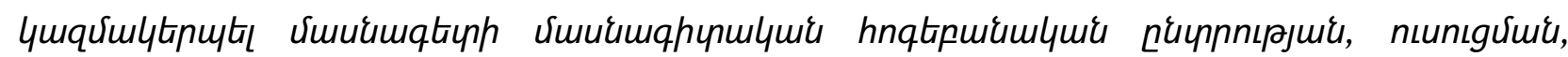

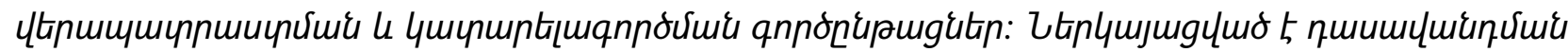

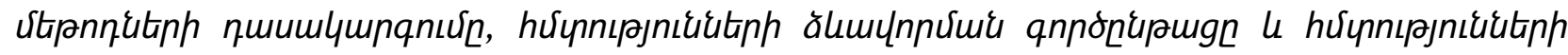

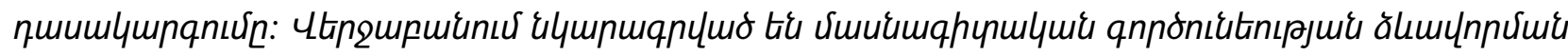

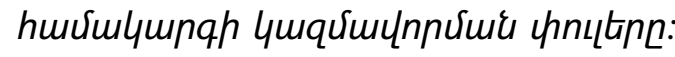

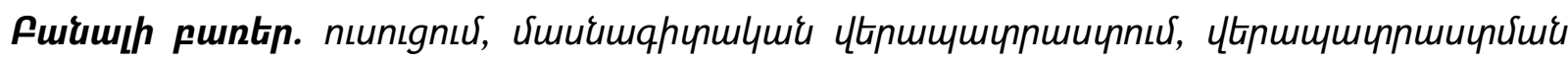

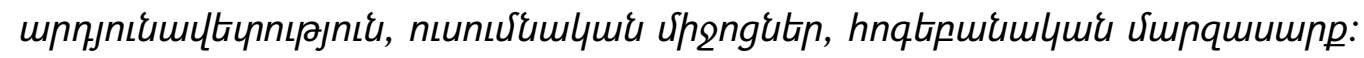

\section{PSYCHOLOGICAL PRINCIPLES FOR DESIGNING SYSTEM OF PROFESSIONAL EDUCATION}

\begin{abstract}
Aguzumtsyan R.V.
The article is devoted to the psychological principles of designing system of professional education. The author proposes four levels of analysis of professional activity, and outlines views on the problems of the structure of activity, the functions of a specialist and its mental functions. Particular attention is paid to the conducted psychological analysis of activities, which made it possible to create a "psychological passport" of a specific psychological activity. The idea is substantiated that, on the basis of a psychological passport, it is possible to organize the processes of professional psychological selection, education, and training of a specialist. The classification of teaching methods, skill formation process and skill classification is presented. In the conclusion, the stages of the system of professional activity are given.
\end{abstract} trainer.

Keywords: education, professional training, training efficiency, teaching aids, psychological 